\section{Spirometric thresholds and biased interpretation of test results}

In an effort to elucidate what constitutes irreversible airways obstruction (ie, COPD), Bhatt et $a l^{1}$ used CT-defined emphysema and gas trapping to determine whether a fixed $F E V_{1}: F V C$ ratio or the lower limit of normal (LLN) is a clinically more discriminating index of COPD. There are, however, several methodological limitations that need to be considered when interpreting these results.

1. The study assumes a paradigm that radiographic signs of emphysema and/ or air trapping are specific of COPD. Alterations in pulmonary structure due to senescence and COPD are to some extent intertwined; ${ }^{2}$ therefore, radiographic findings which do not consider the effects of normal ageing may well explain the higher prevalence rate of emphysema in the fixed ratio group.

2. Tables 2 and 3 in Bhatt $e t a l^{1}$, present 100 single-inference procedures for testing significant differences; for each comparison, type I error is fixed at 0.05 , therefore each comparison runs a $5 \%$ chance of an erroneous conclusion. Multiple single-inference results lead to a greatly increased number of false-positive results. Correcting for the false discovery rate would alter the number of 'significant' findings. ${ }^{3}$ The interpretation of significant differences is further complicated by the fact that several indices are correlated.

3. The study also grossly misrepresents the COPD population. Only including smokers implies that airflow limitation is solely attributable to smoking. The prevalence of COPD in non-smokers has been estimated at $25 \%-45 \%{ }^{4}$ Second, 'One-quarter of the fixed-only group were initiated on home oxygen following the baseline visit'. It is astounding that so many people with no signs of airflow limitation, or at best mild COPD according to Global Initiative for Chronic Obstructive Lung Disease (GOLD) criteria, receive home oxygen. The reason can hardly be COPD.

4. The paper would have benefitted from considering longitudinal studies that are at odds with the authors' conclusions, ${ }^{5}$ and from evidence that 'exacerbations' were COPD related.

In light of these weaknesses, the findings of Bhatt et al need to be interpreted cautiously and certainly do not offer definitive proof that GOLD staging is advantageous over the LLN. Further studies which fairly compare the two criteria to a gold standard in a representative sample of patients with COPD are urgently needed to address this important issue.

\section{Philip H Quanjer, ${ }^{1,2}$ Sanja Stanojevic, Bruce R Thompson ${ }^{4}$}

${ }^{1}$ Department of Pulmonary Diseases, Erasmus University Medical Centre, Rotterdam, The Netherlands ${ }^{2}$ Department of Paediatrics, Division Respiratory Medicine, Erasmus University Medical Centre, Sophia Children's Hospital, Rotterdam, The Netherlands ${ }^{3}$ Division of Respiratory Medicine, The Hospital for Sick Children; Institute of Health Policy, Management and Evaluation, University of Toronto, Toronto, Ontario, Canada

${ }^{4}$ Allergy Immunology and Respiratory Medicine, The Alfred Hospital and Monash University, Melbourne, Australia

Correspondence to Dr Philip H Quanjer, Department of Pulmonary Diseases, Erasmus University Medical Centre, Rotterdam 3015 CD, The Netherlands, and Department of Paediatrics, Division Respiratory Medicine, Erasmus University Medical Centre, Sophia Children's Hospital, Rotterdam, The Netherlands; pquanjer@gmail.com

Contributors PHQ is the guarantor; he contributed to the concept and manuscript writing. SSand BRT contributed to the concept and manuscript writing.

Competing interests None.

Provenance and peer review Not commissioned; externally peer reviewed.

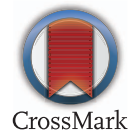

To cite Quanjer PH, Stanojevic S, Thompson BR. Thorax 2014;69:1146.

Received 24 July 2014

Accepted 14 August 2014

Published Online First 2 September 2014

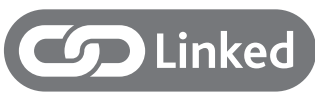

http://dx.doi.org/10.1136/thoraxjnl-2012-202810

- http://dx.doi.org/10.1136/thoraxjnl-2014-205960

- http://dx.doi.org/10.1136/thoraxjnl-2014-206123

Thorax 2014;69:1146.

doi:10.1136/thoraxjnl-2014-206089

\section{REFERENCES}

1 Bhatt SP, Sieren JC, Dransfield MT, et al. Comparison of spirometric thresholds in diagnosing smokingrelated aiflow obstruction. Thorax 2014;69:409-14.

2 Tuder RM, Kern JA, Miller YE. Senescence in chronic obstructive pulmonary disease. Proc Am Thorac Soc 2012:9:62-3.

3 Bender R, Lange S. Adjusting for multiple testing: when and how? J Clin Epidemiol 2001;54:343-9.

4 Salvi S, Barnes PJ. Chronic obstructive pulmonary disease in non-smokers. Lancet 2009;374:733-43.

5 Quanjer PH, Cole TJ. COPD and GOLD Stage I. Chest 2012;141:1122. 